\title{
Pulmonary Thromboembolism and Pulmonary Fibrosis due to H1N1 Pneumonia with Acute Respiratory Distress Syndrome: Not ALL is COVID
}

\author{
Vinod L. Pal ${ }^{1}$, Dharani M${ }^{1}$, Ketaki Utpat ${ }^{1}$, Unnati Desai ${ }^{2 *}$, Jyotsna M Joshi ${ }^{1}$, Ramesh Bharmal ${ }^{1}$ \\ ${ }^{1}$ Department of Pulmonary Medicine, T. N. Medical College, B. Y. L. Nair Hospital, Mumbai, India. \\ ${ }^{2}$ Associate Professor and Incharge, Department of Pulmonary Medicine,T. N. Medical College and B. Y. L. Nair Hospital.
}

*Corresponding Author: unnati Desi, Department of Pulmonary Medicine, T. N. Medical College, B. Y. L. Nair Hospital, Mumbai, India.

Received date: May 22, 2021; Accepted date: July 16, 2021; Published date: July 24, 2021

Citation: Vinod L. Pal, Dharani M, Utpat K., Desai U., Jyotsna M Joshi, Bharmal R. (2021) Pulmonary Thromboembolism and Pulmonary Fibrosis due to H1N1 Pneumonia with Acute Respiratory Distress Syndrome: Not ALL is COVID. J. Gastroenterology Pancreatology and Hepatobilary Disorders. 5(4): DOI: 10.31579/2641-5194/035

Copyright: (c) 2021, Unnati Desai, This is an open access article distributed under the Creative Commons Attribution License, which permits unrestricted use, distribution, and reproduction in any medium, provided the original work is properly cited.

\begin{abstract}
:
Novel influenza A H1N1 virus (pH1N1) was the predominant strain in the 2009 pandemic. It continues to circulate along with other influenza strains in the post pandemic era. This new virus is nevertheless well known for its strong association with high cardiovascular mortality and a high propensity to preferentially affect young and otherwise healthy adults, resulting in a clustering of severe and even fatal cases in patients of the productive age group. H1N1 infection is a multifaceted disease. It affects the lung parenchyma as well as the pulmonary vasculature. It also affects the multisystemic vasculature and can cause other embolic events not strictly falling in the "usual" thrombotic category. We herein present a case of H1N1 influenza pneumonia induced severe ARDS with pulmonary thromboembolism (PTE) and pulmonary fibrosis.
\end{abstract}

Keywords: H1N1, ARDS, hypercoagulable state, venous thrombotic events, pulmonary thromboembolism (pte)

\section{Introduction}

The novel influenza A (pH1N1 i.e. swine flu) virus illness, which is associated with high morbidity and mortality, is known to occur as pandemic as well as epidemic worldwide. The infection causes severe non cardiogenic hypoxemic respiratory failure also known as the acute respiratory distress syndrome (ARDS)[1,2]. In recent years, there has been an emergence of clinical data suggesting that $\mathrm{pH} 1 \mathrm{~N} 1$ infection may also predispose patients to the development of thromboembolic complications. Previous observational and autopsy studies have documented the occurrence of both venous and arterial events among patients with $\mathrm{pH} 1 \mathrm{~N} 1$ infection but the epidemiologic association between pH1N1 and thromboembolism as well as the pathophysiologic mechanisms underlying this potential association remains to be established. The prominence of pulmonary thromboembolism and infarction in this case may be related to hypercoagulability, which has also been reported elsewhere in patients with pandemic influenza pneumonia. Here we present a case of $\mathrm{H} 1 \mathrm{~N} 1$ influenza pneumonia induced severe ARDS with pulmonary thromboembolism (PTE). Our case also has concurrent post H1N1 pulmonary fibrosis described earlier in literature [3].

Case Report
A 50 year old lady presented to the emergency medical services with complaints of sore throat, fever and dry cough since 1 week and progressive shortness of breath since 3 weeks. She was a housewife without any comorbidities and addictions. Patient had earlier followed up with private physician evaluated with throat swab for $\mathrm{pH} 1 \mathrm{~N} 1$ by reverse transcriptase polymerase chain reaction (RT PCR) method which was positive for $\mathrm{pH} 1 \mathrm{~N} 1$ infection. Patient was managed with broad spectrum antibiotics and oseltamivir 150mg twice daily for 2 weeks. Patient had no past history of tuberculosis, antituberculous drug intake or tuberculosis contact. There was a history of immobilization since 2 weeks. In view of chest radiograph (CXR) changes showing bilateral reticulonodular opacities with consolidation and persistent desaturation, she was referred to us for further management (figure 1). On examination the patient was afebrile with pulse of 111 beats per minute, blood pressure of 110/70 $\mathrm{mmHg}$, respiratory rate of 28 cycles per minute and pulse oximetry showing saturation of $70 \%$ on room air, $90 \%$ with 1 litre/min of oxygen supplementation through nasal prongs. Respiratory system revealed bilateral basal crackles. Other system examination was unremarkable. Her complete hemogram (CBC) showed a hemoglobin of $13 \mathrm{gm} \%$, total count of 10500/cumm, platelets of 391000/cumm. Her renal and liver function tests were normal. Arterial blood gas (ABG) analysis was suggestive of type 1 respiratory failure with $\mathrm{PaO} 2 / \mathrm{FiO} 2$ ratio of 200 indicating 
moderate ARDS. A repeat throat swab for $\mathrm{pH} 1 \mathrm{~N} 1 \mathrm{RT}-\mathrm{PCR}$ was negative. A laboratory connective disease profile was negative. The Well score was 3 (moderate probability for PTE). Computed Tomography Pulmonary Angiography (CTPA) with high resolution computed tomography (HRCT) was suggestive of resolving bilateral diffuse ill defined bronchocentric and subpleural areas of consolidation, ground glass attenuation and patchy pulmonary fibrosis throughout the lung parenchyma with lower lobe predominance consistent with resolving ARDS with pulmonary fibrosis. Bilateral acute PTE with moderate thrombus burden was evident (figure 2a,3a). A two dimensional echocardiography (2D ECHO) as suggestive of mild pulmonary hypertension $(\mathrm{PH})$ with pulmonary artery systolic pressure of $35 \mathrm{~mm}$. In view of PTE she was started on anticoagulation with injectable low

molecular weight heparin (LMWH) and tablet warfarin. Patient was given oxygen supplementation with $\mathrm{FiO} 260 \%$ then gradually $\mathrm{FiO} 2$ requirement decreased to $40 \%$. She was also treated with oral steroids tablet prednisolone $40 \mathrm{mg}$ once daily for 1 month followed by tapering dose ( 5 mg per week) for 6 months. After discharge from hospital patient was using oxygen supplementation at $\mathrm{FiO} 2$ of $28 \%$ which gradually decreased. At her one month follow up she was symptomatically much better with normal $\mathrm{SpO} 2$ on room air with a significant radiological improvement too. The repeat CTPA with HRCT was suggestive of residual pulmonary fibrosis with significant improvement in thrombus burden after 3 month of therapy with anticoagulants and steroids (figure $2 b, 3 b)$.

Hence we diagnosed this as a case of Pulmonary Fibrosis and Pulmonary Thromboembolism due to H1N1 pneumonia with ARDS.

\section{Legends to Figures:}

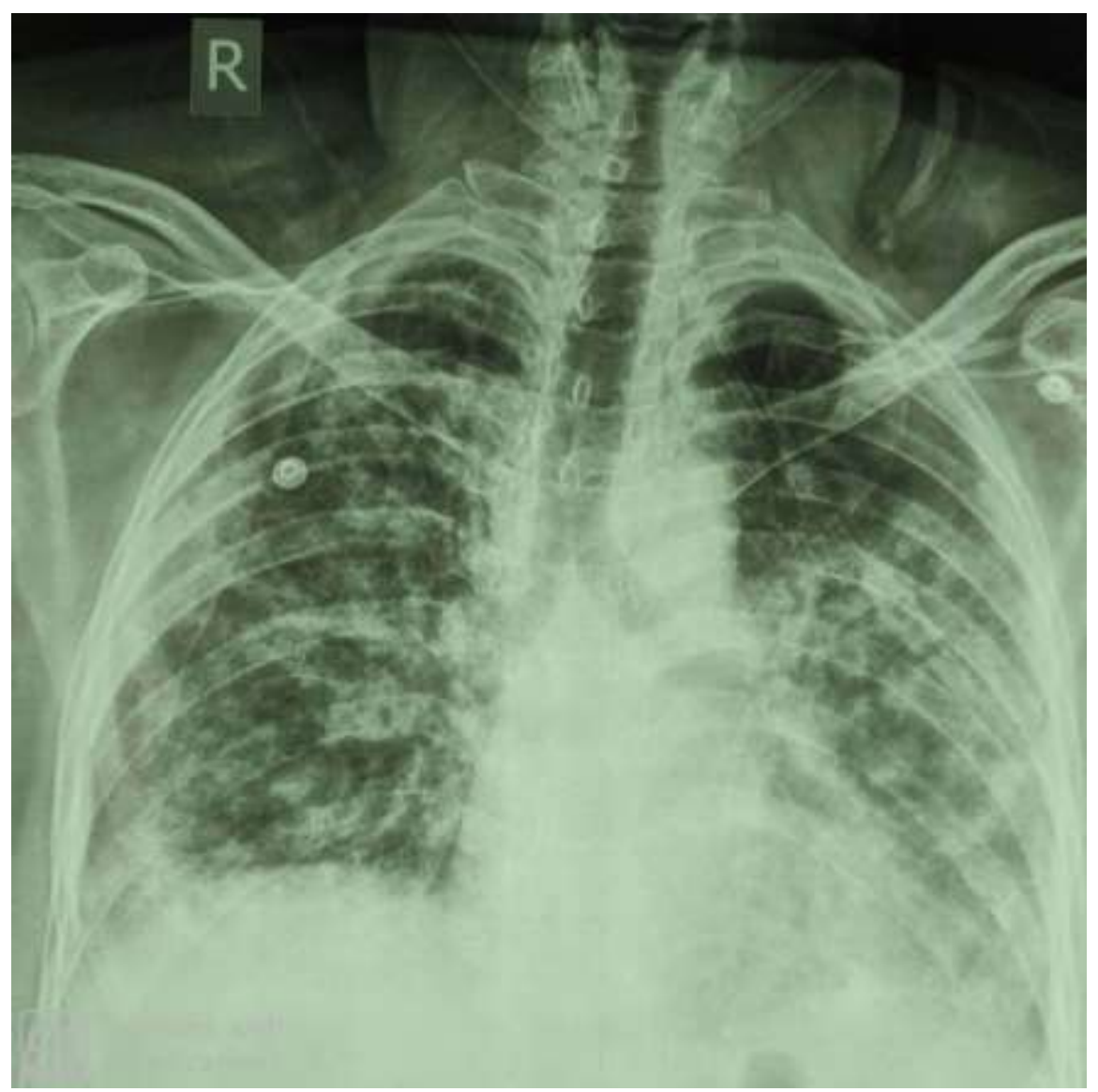

\section{Figure 1:}



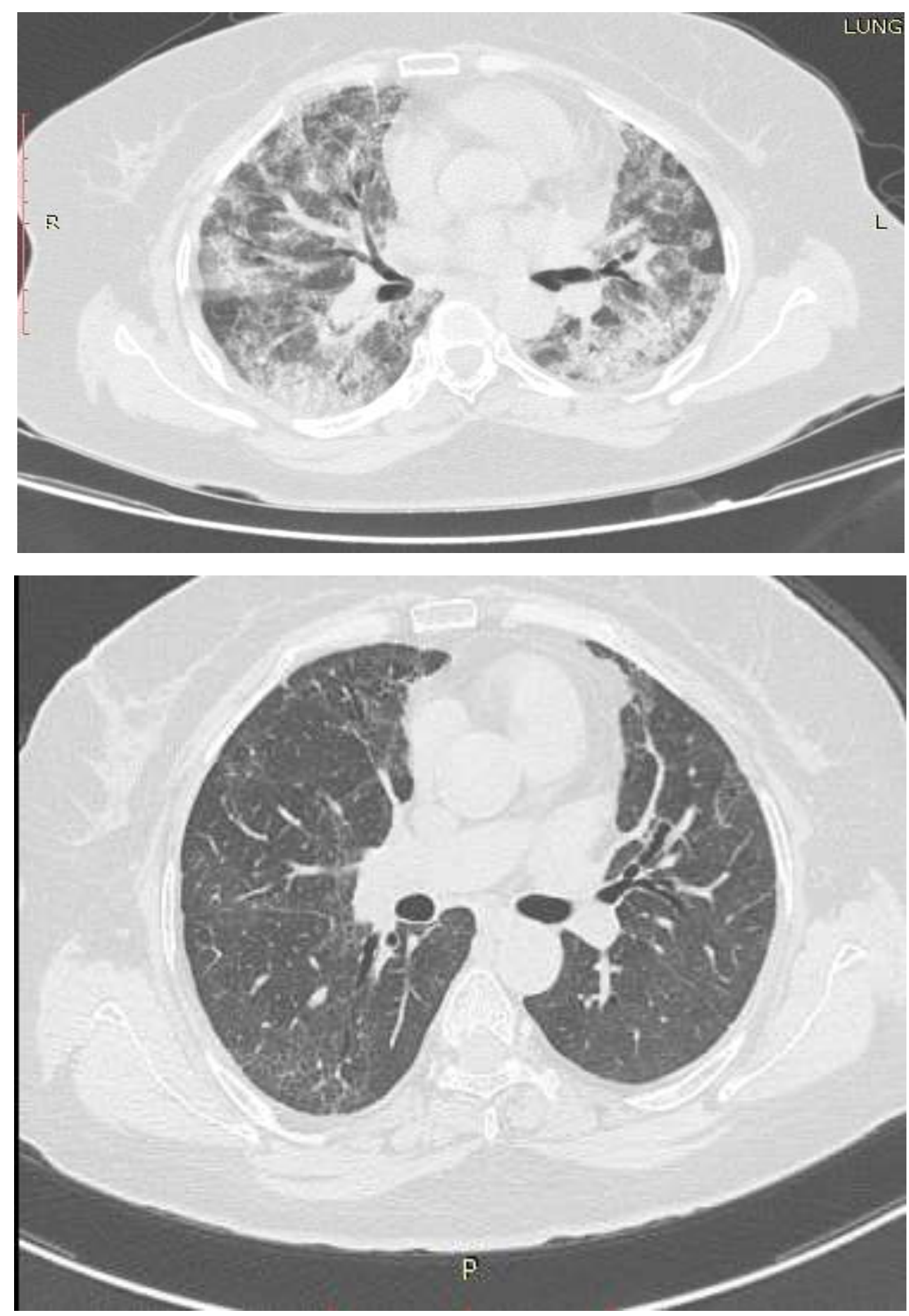

Figure 2: A and B

Figure 2:A) Initial high resolution computed tomography( HRCT) Chest showing interstitial and septal thickening with GGO and bilateral consolidation B) Post treatment high resolution computed tomography (HRCT) chest showing significant improvement GGO and consolidation. 


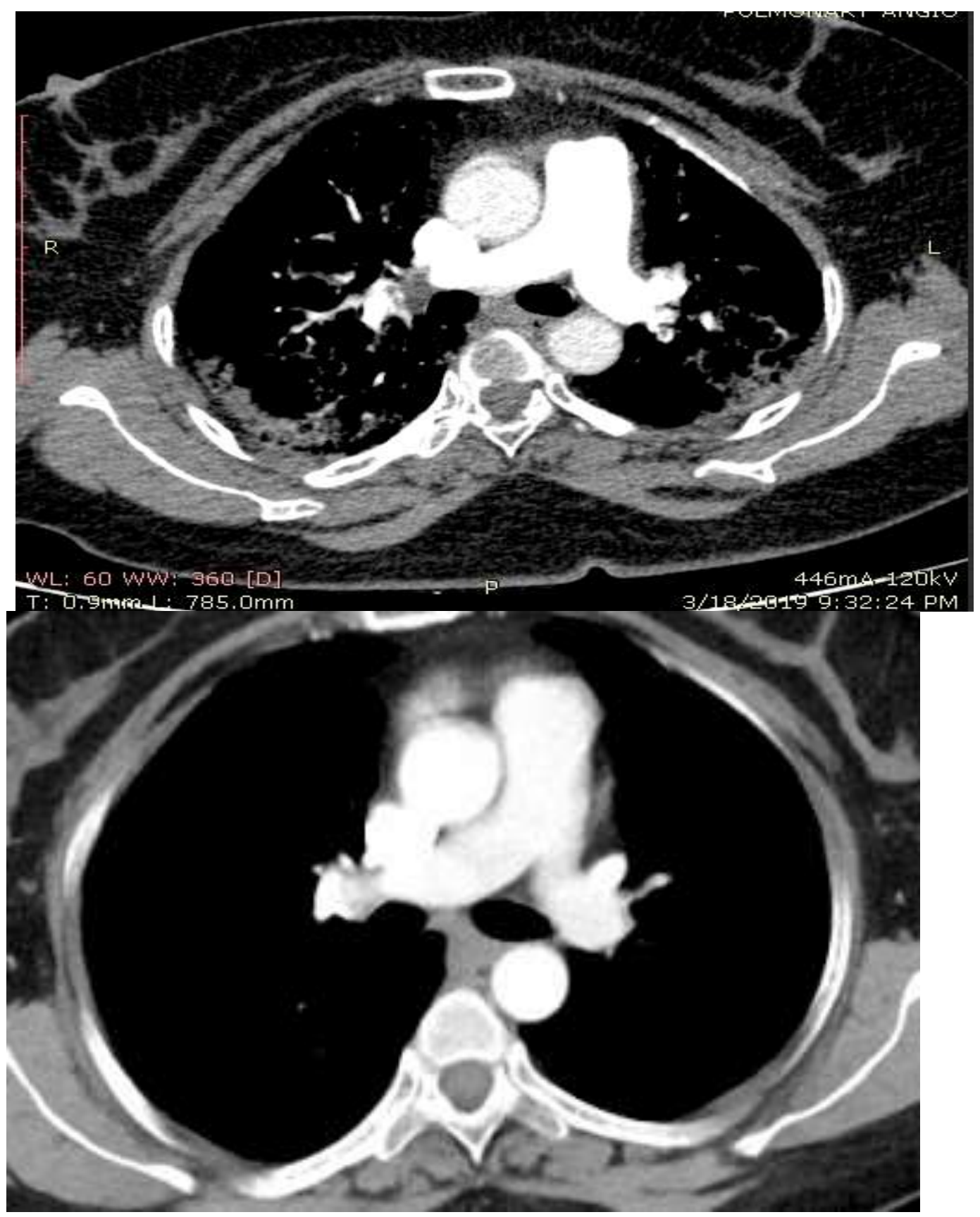

Figure 3: $\quad$ A and B

Figure 3:A)Initial Computed tomography Pulmonary angiography (CTPA) showing right main pulmonary artery filling defect suggestive of thrombus B) Post treatment contrast enhanced computed tomography shows significant improvement in thrombus burden .

\section{Discussion}

ARDS is an entity characterized by acute onset respiratory symptoms with a non cardiogenic pulmonary edema and hypoxemic respiratory failure. It can emanate from a heterogeneous gamut of causes. These include infectious like severe bacterial fungal and viral pneumonia, sepsis, shock, trauma, burns and transfusion related insult. Influenza H1N1 infection can precipitate severe ARDS with very a high mortality [4]. Majority of patient of ARDS due to H1N1 had bilateral patchy opacity on computed tomography scan [6]. It is notorious for stimulating intravascular coagulation and its associated complications. The pathophysiology of thrombosis is based on the presence of three factors:
Endothelial injury, venous status and hypercoagulability also termed as the Virchows triad. Damage to vascular walls prevents endothelium from inhibiting coagulation and initiating local fibrinolysis. Inflammatory response also plays a role in the formation of thrombus via production of microparticles (MPs) that carry cell-specific molecular proteins such as galectin [7]. The stimulation of monocytes, especially by galectin, leads to cell activation and tissue factor expression which triggers the coagulation pathway. Furthermore during inflammation, oxygen free radicals are produced which induce thrombosis in microvessels via activation of platelet aggregation [8]. Infectious agents, including viruses, bacteria and parasites, may initiate this process. An in vitro study reported that endothelial and monocytes cells that were incubated with influenza 
were able to activate coagulation via endothelial dysfunction and elevated tissue factor levels. Immobilization leads to local venous stasis by accumulation of clotting factors and fibrin, resulting in thrombi/emboli formation. In the Prospective Investigation of Pulmonary Embolism Diagnosis II (PIOPED II) study, immobilization was identified as the most common risk factor. The prophylactic administration of LMWH or unfractionated heparin in severely ill subjects is thereby recommended encouraged. The benefits of anticoagulation are weighed against the risks.

Seasonal influenza viruses may cause severe pulmonary disease and pulmonary embolism. The possible association between acute respiratory tract infections caused by seasonal influenza virus and the occurrence of PTE remains unknown till date. Mortality associated with pandemic influenza A was mostly due to respiratory conditions (76\%). The direct cause of death was recorded as pulmonary embolism in only in $1 \%$ of these cases. However, in a study conducted in United States; of the hospitalized patients with $\mathrm{H} 1 \mathrm{~N} 1$ influenza A infection, $66 \%$ had pulmonary infiltrates suggestive of pneumonia or ARDS. Another study showed that the most common findings on CXRs were patchy consolidation but CXRs were normal in more than half of patients with pandemic $\mathrm{H} 1 \mathrm{~N} 1$ virus [2]. In our case pulmonary embolism was detected by CTPA performed due to a moderate wells pretest probability score. Additionally the symptoms of dyspnea, tachycardia with history of immobilization for 2 weeks led us to suspecting a possibility of pulmonary embolism. Our patient had no other risk factors for pulmonary embolism that we identified. Thus immobilization along with H1N1 infection would have triggered the coagulation cascade activation leading to hypercoagulable state. Despite of progress in the management of ARDS mortality still remains high. Influenza can cause severe ARDS because of high virulence load, abberant immune response and extensive lung damage. H1N1 ARDS patients may have long term lung disabilities [5]. Pulmonary fibrosis, a known sequelae could be progressive or regressive [3]. Our patient also had regressive pulmonary fibrosis as a sequelae. We describe for the first time PTE and Pulmonary fibrosis in a case of treated H1N1 pneumonia with ARDS. The timely recognition of clinical signs of ARDS, early introduction of antiviral therapy and lung protective ventilation play crucial roles in management.

\section{References:}

1. Dandagi GL, Byahatti SM. (2011) An insight into the swineinfluenza A (H1N1) virus infection in humans. Lung India;28:34.

2. Chowell G, Bertozzi SM, Colchero MA, Lopez-Gatell H, AlpucheAranda C, Hernandez M, Miller MA. (2009) Severe respiratory disease concurrent with the circulation of H1N1 influenza. New England Journal of Medicine 361:674-9.

3. Singh N, Singh S, Sharma BB, Singh V. (2016) Swine flu fibrosis: Regressive or progressive? Lung India 33(2):219-221.

4. Jaber S, Conseil M, Coisel Y, Jung B, Chanques G. (2010) ARDS and influenza A (H1N1): patients' characteristics and management in intensive care unit. A literature review. InAnnalesfrançaisesd'anesthèsie et de reanimation 29:117-125.

5. Luyt CE, Combes A, Becquemin MH, Beigelman-Aubry C, Hatem S, Brun AL, Zraik N, et al. (2009) Long-term outcomes of pandemic influenza A (H1N1)-associated severe ARDS. Chest 2012;142:583-92.

6. Grieser C, Goldmann A, Steffen IG, Kastrup M, Fernández CM, Engert U, et al. (2012) Computed tomography findings from patients with ARDS due to Influenza A (H1N1) virus-associated pneumonia. European journal of radiology 81:389-94.

7. Diaz JA, Ramacciotti E, Wakefield TW. (2012) Do galectins play a role in venous thrombosis? a review. Thrombosis research 125:373-6.

8. Jourdan A, Aguejouf O, Imbault P, Doutremepuich F, Inamo J, Doutremepuich C. (1995) Experimental thrombosis model induced by free radicals. Application to aspirin and other different substances. Thrombosis research 79:109-23.

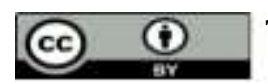

This work is licensed under Creative Commons Attribution 4.0 License

\author{
Ready to submit your research? Choose Auctores and benefit from: \\ * fast, convenient online submission \\ * rigorous peer review by experienced research in your field \\ * rapid publication on acceptance \\ * authors retain copyrights \\ * unique DOI for all articles \\ * immediate, unrestricted online access
}

At Auctores, research is always in progress.

Learn more www.auctoresonline.org/journals/gastroenterologypancreatology-and-hepatobilary-disorders 